\title{
A ATIVIDADE DO TUTOR DE EAD: ANÁLISE DE SEU AGIR EDUCACIONAL
}

\author{
Annie Rose SANTOS \\ (Universidade Estadual de Maringá) \\ anniersantos@hotmail.com
}

Resumo: Neste artigo, objetivamos contribuir para uma reflexão acerca do papel do tutor da Educação a Distância $(E a D)$ no exercício de sua função mediante a análise e a identificação das representações construídas sobre o seu trabalho em seus próprios discursos, gerados a partir de entrevistas semiestruturadas (BULEA, 2010). O quadro teórico-metodológico tem por base - Interacionismo Sociodiscursivo (ISD) em sua vertente mais didática (BRONCKART, 2006; 2008) e o Interacionismo Social (IS) (BAKHTIN, 1993; 2003). Neste trabalho, apresentamos: (a) uma síntese dos aportes teóricometodológicos, em que discorremos acerca do quadro teórico do ISD e dos procedimentos de análise do agir humano representado em textos, b) aportes teóricos da entrevista de pesquisa para melhor fundamentar o uso desse instrumento; c) resultados parciais dos discursos dos tutores. Na metodologia, expomos os dados gerados pelas entrevistas aplicadas a dez tutores do curso de Letras a Distância de uma IES pública do interior paranaense. Os resultados das análises dos depoimentos dos tutores permitiram a constatação da relevância desse profissional na modalidade de ensino a distância em nosso país.

Palavras-chave: Tutor; Educação a Distância, Formação de Professores, Interacionismo Sociodiscursivo.

Abstract: In this paper, the role of the tutors in Distance Education is investigated by analyzing and identifying representations built on their work and expressed in their discourses in half-structured interviews (BULEA, 2010). The theoretical and methodological framework is based on Social-Discursive Interactionism (SDI) within its most didactic pathway (BRONCKART, 2003; 2005), Social Interactionism (SI) (BAKHTIN, 1993; 2003). This paper comprises (a) a synthesis of theoretical and methodological guidelines on the theoretical framework of SDI and on the procedures of human action represented in texts for the construction of a broader perception on tutors' educational work; (b) theoretical guidelines for a research interview to foreground the better use of such a tool; (c) some insights gathered from some tutors' discourse. Data produced in a public university in the state of Paraná, Brazil, are given in the Methodology section. They comprise half-structured interviews with tutors of the Language and Literature Distance Education course. Results from the analysis of tutors' statements offer evidence of the relevance of the tutor in distance education modality in Brazil.

Keywords: tutor; Distance Education, teachers' formation, Social-discursive Interactionism. 


\section{Introdução}

Nossa atuação como docente nos cursos de graduação a distância em uma instituição pública de Ensino Superior (IES) paranaense e o convívio com o universo dessa forma de ensino com os tutores situaram-nos ante o eixo temático escolhido para investigação neste artigo: o agir profissional do tutor de Educação a Distância (EaD) à luz do Interacionismo Sociodiscursivo (ISD) (BRONCKART, 2006; 2008).

Utilizamos o ISD e o Interacionismo Social (IS) (BAKHTIN, 1993; 2003) considerando que atribuem ao agir e à linguagem um papel essencial no desenvolvimento humano para melhor compreensão do trabalho docente do tutor. Abordamos também pressupostos teóricos das entrevistas de pesquisa para a fundamentação desse instrumento de análise; buscamos identificar a atividade do tutor em EaD, verificando seu agir educacional em construção pela linguagem à luz do ISD. Iniciamos este trabalho discorrendo sobre essa teoria.

\section{O interacionismo sociodiscursivo}

O Interacionismo Sociodiscursivo surgiu na década de 1980 na Universidade de Genebra, Suíça, a partir de estudos coordenados por JeanPaul Bronckart, cuja fonte de referência é Vygostky, no campo do desenvolvimento, e Bakhtin, no campo da linguagem (GUIMARÃES, 2007). Os estudos desses pesquisadores defendem a reunificação da Psicologia em sua dimensão social, objetivando esclarecer as condições da emergência e do funcionamento do pensamento consciente humano. Atualmente, essa posição foi expandida, e a finalidade maior é o projeto de construção de uma Ciência do Humano integrada a outras áreas.

Essa teoria (ISD) é conceituada por Bronckart (2008) como uma vertente mais específica do Interacionismo Social (IS), como uma posição epistemológica da qual integram diversas correntes da filosofia e das ciências humanas. Para este autor, essa posição parte da historicidade do ser humano, centrando-se no processo de transformação do organismo humano em pessoa, isto é, as condições sob as quais se desenvolveram, na espécie humana, as 
formas particulares de organização social bem como as formas de interação de caráter semiótico. Bronckart (2008) entende que a intervenção prática é a questão central de toda e qualquer ciência do humano no que tange ao mundo físico, ao pensamento, à sociedade e à linguagem. Abreu-Tardelli (2006) afirma que essa compreensão integra uma mudança de perspectiva introduzida por Marx e Engels, focalizando o papel que os instrumentos, a linguagem e 0 trabalho desempenham na construção da consciência. Cristóvão (2008, p.4-5), por seu turno, descreve o ISD nesses termos:

a) As ciências humanas teriam como objeto as condições de desenvolvimento e funcionamento das condutas humanas;

b) $[. .$.$] os processos de desenvolvimento humano se efetivariam com base$ nos pré-construtos humanos;

c) [...] o desenvolvimento humano se efetuaria no quadro do agir [...]

d) Os processos de construção dos fatos sociais e os processos de formação do indivíduo seriam duas vertentes complementares e indissociáveis do desenvolvimento humano;

e) A linguagem desempenharia um papel fundamental e indispensável no desenvolvimento [...].

Ainda a respeito do ISD, Bronckart (2009 [1999]) afirma que

- ISD visa a demonstrar que as práticas pedagógicas linguageiras situadas (ou os textos discursos) são os instrumentos principais do desenvolvimento humano, tanto em relação aos conhecimentos e aos saberes quanto em relação às capacidades do agir e da identidade das pessoas (BRONCKART, 2009 [1999], p.10, grifos do autor).

Bronckart (2006) sublinha que os aportes teóricos fundamentais para 0 ISD são provenientes dos estudos de Bakhtin e de Vygotsky, já que essa teoria se apropria da abordagem descendente dos fatos linguageiros, alçando a primeiro plano a práxis, a dimensão ativa e prática das condutas humanas em geral e das condutas verbais em particular provenientes dos trabalhos de Volochinov e de Bakhtin.

No tocante aos estudos de Bakhtin para o ISD, Bronckart (2006) explana que este conceitualizou as 'formas de enunciação' referidas por Volochinov e propôs a noção de 'gêneros do discurso' ou 'gêneros de textos', apontou a dependência desses gêneros em relação que tange aos tipos de atividade humana, diferenciando os gêneros primários e os secundários, e analisou as 
variadas propriedades dos gêneros, particularmente seu caráter essencialmente interativo ou dialógico.

Em relação aos estudos de Vygotsky para o ISD, Bronckart (2006) assevera que sua tese foi formulada com a finalidade de evidenciar as condições de constituição do pensamento consciente humano em um programa de pesquisa que enfocaria: (i) as condições e os processos de interação social, o que, na contemporaneidade, significam as diversas redes e as formas da atividade humana; (ii) as formas de enunciação que verbalizam ou semiotizam essas interações sociais no quadro de uma língua natural; e (iii) a organização dos signos no interior dessas formas, as quais, para Vygotsky, constituiriam as ideias e o pensamento humano consciente.

Ao afirmar o caráter universalizante chamado por Bakhtin de procedimento praxiológico descendente, que aponta que as propriedades das atividades humanas, como a dos gêneros de textos, são válidas para qualquer língua natural utilizada, Bronckart (2006) indaga qual o estatuto atribuído às especificidades das línguas naturais e à língua enquanto sistema nessa visão. O ISD se respalda em Vygotsky nessa perspectiva, na busca por validar experimentalmente a tese de que a apropriação e a interiorização dos signos de uma língua natural constituem o pensamento consciente.

O programa de pesquisa do ISD, conforme Bronckart (2008), está alicerçado em um método de análise descendente que se desdobra em três níveis: o primeiro se reporta às dimensões da vida social, por meio do qual há uma análise dos pré-construídos sócio-históricos englobando os fatos sociais e as atividades gerais e de linguagem. Nesse nível, segundo Ferreira (2011), devemos atentar para quatro elementos inter-relacionados: as atividades coletivas, as formações sociais, os textos e os mundos formais. Nosso objetivo neste trabalho é observar esses níveis em relação à atividade do tutor.

O segundo nível, segundo Bronckart (2008), remete aos processos de mediação formativa, também identificados por Cristóvão (2008) como processos de mediação sociossemióticos, no qual acontece a transmissão, a apropriação e a re-produção de pré-construídos. 
No terceiro nível, de acordo com Bronckart (2008), há uma análise dos efeitos das mediações formativas e da apropriação relacionada à constituição do sujeito, e, na visão do autor, esses efeitos podem estar divididos em três campos investigativos que contemplam a análise das condições de emergência do pensamento consciente; do desenvolvimento, não apenas do pensamento humano, mas também dos conhecimentos e das capacidades do agir e dos mecanismos utilizados pelas pessoas para auxiliar na transformação dos préconstruídos formados pela coletividade.

Ferreira (2011) argumenta que, na análise do desenvolvimento humano, o ISD não descarta a possibilidade de um movimento dialético permanente entre esses três níveis supracitados, ou seja, há uma circulação desses três níveis através dos quais:

[...] os pré-construídos humanos mediatizados orientam o desenvolvimento das pessoas; estas, por sua vez, com o conjunto de suas propriedades ativas, alimentam continuamente os pré-construídos coletivos (elas os desenvolvem, os transformam, os contestam etc.) (BRONCKART, 2008, p.12).

Considerando que uma característica importante do trabalho é uma das formas de agir do homem na sociedade e que as condutas humanas construídas sócio-historicamente necessitam da linguagem (artefato simbólico) para se desenvolver por meio do que Habermas (1987) chama de agir comunicativo, é mediante a análise dessa linguagem (textos orais e ou escritos) que podemos efetivar a interpretação do agir do homem em situação de trabalho. É o que buscamos neste texto: analisar o discurso dos tutores da EaD visando a compreender o seu trabalho.

Ressaltamos, comungando com Ferreira (2011), que a efetivação e a avaliação desse agir humano ocorrem em conformidade com os sistemas identificados por Habermas (1987) como o mundo objetivo, subjetivo e social. Este autor concebe o mundo objetivo como constituído pelos conhecimentos elaborados durante a sócio-história humana que se tem sobre o meio físico e sobre as determinações que este impõe a cada ação. $O$ mundo subjetivo reporta-se ao conjunto de conhecimentos que um sujeito possui sobre si mesmo e também à visão que os outros indivíduos possuem sobre si. O mundo 
social, por seu turno, seriam todos os conhecimentos relativos às normas sociais.

Citamos Bronckart (2009), para quem as ações humanas podem ser apreendidas sob dois pontos de vista: o sociológico e o psicológico. O primeiro é atestável por um fluxo constante das ações, das quais comumente participam vários agentes no quadro de uma ou de várias formações sociais. No nível psicológico, as ações são ligadas à utilização das formas comunicativas que se encontram em uso em dada formação social. Nesse sentido, o autor pontua que um dos problemas do IS é o de analisar as relações de interdependência entre as propriedades das ações e as propriedades das formações sociais que constituem o contexto dessas ações.

Habermas (1987) propõe que, no desenvolvimento de qualquer atividade coletiva, há pretensões à validade em relação ao mundo, significando que a atividade pressupõe uma rede de conhecimentos comuns pelos quais ela se articula e que, concomitantemente, ela contribui para criar e transformar. Nascimento (2013), com o respaldo de Bronckart e Machado (2004), afirma que o agir humano não é diretamente observável, e que as noções de ação, atividade, agente, etc. constituem-se em um produto de nossas interpretações sobre as condutas diretamente observáveis, interpretações estas que podem ser expressas por textos orais ou escritos, os quais acabam por construir determinadas 'figuras interpretativas do agir humano'.

A pesquisa que empreendemos é de natureza etnográfica e netnográfica, vinculada ao paradigma qualitativo de cunho interpretativista, pois articula, na acepção de Hine (2003 [2000]), Bortoni-Ricardo e Kozinets (2010), tais elementos: (i) as práticas sociais dos sujeitos pesquisados (os tutores em EAD); (ii) os pesquisadores como agentes ativos dessas práticas (a pesquisadora); (iii) o microcosmo que a pesquisa contempla (o ambiente real e virtual da tutoria); e (iv) o contexto - espaço real e virtual em que os registros das falas dos sujeitos desta pesquisa ocorrem -, o processo interacional alvo deste estudo.

Na sequência, tratamos dos aportes teóricos dos instrumentos utilizados para a geração dos dados, as entrevistas de pesquisa. 


\section{Aportes teóricos das entrevistas de pesquisa}

Neste estudo, as entrevistas utilizadas junto aos dez tutores do curso de Letras a Distância de uma IES pública paranaense foram orais, diretivas e semidiretivas, de forma que os entrevistados respondessem ao que thes era indagado pela pesquisadora, docente da instituição, sobre seu trabalho, sua atividade (BULEA, 2010), considerando como fundamentação teórica os postulados do ISD.

A entrevista de pesquisa constitui-se em um dos três métodos e técnicas de análise do agir que se baseiam exclusivamente na utilização da linguagem, e como Ecaterina Bulea (2010, p.30) assinala, 'quase exclusivamente da linguagem oral'. De acordo com Bulea (2010), a entrevista de pesquisa foi elaborada no final da década de 1920, no campo da Psicologia Social, em um quadro que contemplou desde o início as problemáticas do trabalho. A elaboração desse método situa-se nos trabalhos dirigidos por Roesthlisberger e Dickson em meio industrial (BLANCHET et al., 2012 [1985]), os quais abordavam, inicialmente, as condições materiais da produtividade da empresa e a influência do 'moral' desses operários sobre sua produtividade.

Em se tratando da definição e dos usos atuais da entrevista de pesquisa, a maioria dos autores menciona dois aspectos específicos: a) trata-se do caráter linguageiro, discursivo ou interlocutório desse dispositivo, a entrevista definindo-se minimamente como 'uma situação social de encontro e de troca' (BLANCHET e GOTMAN, 2012, p.17); b) trata-se da inscrição dessa interação linguageira no quadro da pesquisa, como enunciam Blanchet et al. (2012, p.12):

[A entrevista é] um dispositivo de interlocução colocado para fins de pesquisa [...] para favorecer a expressão e a elaboração do discurso de uma dada pessoa, sobre um problema ou uma situação de dados, e eventualmente facilitar ou acompanhar mudanças institucionais (BLANCHET et al., 2012, p.12, grifos da autora).

Bulea (2010) acentua que a entrevista de pesquisa - diferentemente de outros métodos, como a entrevista de explicitação e a instrução ao sósia - não 
possui objetivo orientado especialmente para a análise do agir, tampouco tem uma finalidade desenvolvimental declarada. A mudança ou a transformação, seja no nível das pessoas, seja no nível das organizações, não são evocadas, a não ser sob a modalidade do 'eventual'.

No plano metodológico, conforme Bulea (2010), o uso das entrevistas para a análise do agir possui um caráter interessante e fecundo devido a não focalização de um aspecto técnico específico objetivando a descrição do agir. Sobre essa 'neutralidade técnica', esse tipo de entrevista pode configurar-se em uma verdadeira oportunidade para a compreensão de estratégias de interpretação do agir, dependendo da única iniciativa dos entrevistados, estratégias estas que mobilizam os mecanismos textuais e discursivos que os entrevistados utilizam espontaneamente e que são, por isso mesmo, próximos das configurações discursivas usadas cotidianamente em seu trabalho.

Em relação à situação deste estudo, considerando que se trata de um texto dialógico, levantamos hipóteses tanto da situação da pesquisadora quanto dos tutores informantes, ou seja, sobre as representações iniciais tanto da pesquisadora quanto dos tutores que necessariamente influenciam a forma do texto produzido (BRONCKART, 1997).

Nesse sentido, assim podemos hipotetizar a situação da pesquisadora deste estudo, em consonância com Machado (2009): em um lugar físico privado e no espaço social da instituição acadêmica, distante dos receptores, e sozinha antes da aplicação do questionário e das entrevistas de pesquisa, no momento de sua elaboração. Dessa forma, exercemos o papel de pesquisadora-entrevistadora, representando os informantes que assumem o papel de tutores da modalidade a distância em exercício em sua função. E a situação de produção dos tutores é assim hipotetizada: em uma instituição de Ensino Superior pública, na presença da pesquisadora, no espaço social da instituição acadêmica, produzindo uma resposta com o objetivo de que a pesquisadora se informe sobre sua opinião acerca do tópico da pergunta e de que construa uma boa imagem sobre ele mesmo, o tutor.

Machado (2009) alega que o levantamento das hipóteses relativas à situação de produção dos interlocutores permite observar que, logo de início, 
se estabelece entre pesquisador e entrevistados uma relação complexa, assimétrica, hierarquizada, que pode ser vista sob quatro pontos de vista, quais sejam: 1) sob o ponto de vista da hierarquia institucional, pois há uma posição superior da pesquisadora em relação aos entrevistados, decorrente das posições que ocupam na instituição acadêmica, e no caso deste estudo, devido ao fato de que, em interações anteriores, a primeira assumira o papel de formadora dos segundos, e, por conseguinte, uma posição institucionalmente superior; b) sob o ponto de vista dos conhecimentos teóricos, a pesquisadora também ocupa uma posição superior em relação aos tutores, considerando que, teoricamente, ela detém maior quantidade desses conhecimentos (embora entre os tutores havia doutores e doutorandos, portanto, com a mesma titulação que a pesquisadora); c) sob o ponto de vista dos conhecimentos 'práticos', invertem-se as posições, já que, no caso deste estudo, são os tutores que ocupam uma posição superior, no sentido de que são eles, teoricamente, que detêm esses conhecimentos; d) sob o ponto de vista do próprio gênero questionário, a posição superior é ocupada pela pesquisadora, e, no caso deste estudo, é ela quem coloca o tutor na posição de 'ter de' responder, com o simples ato de perguntar. Nesse contexto, somos favoráveis à assertiva de Machado (2009) de que somente refletindo sobre a situação de produção e sobre o ato de fala de perguntar já é possível levantar várias hipóteses sobre os tipos de respostas que provavelmente serão obtidas.

\section{Os sujeitos entrevistados - os tutores}

No campo das ciências humanas, assim como nas ciências do trabalho, há tempos emergiu a consciência da necessidade de se apreender a voz dos agentes sociais diretamente envolvidos na atividade que se quer investigar, compreendendo que somente a observação e a interpretação dos pesquisadores não são suficientes para apreendê-la em toda a sua complexidade (MACHADO, 2009). Neste estudo, buscamos apreender a voz dos tutores diretamente envolvidos na atividade a ser investigada: no exercício 
da tutoria do curso de Letras a Distância de uma IES pública paranaense, no período de fevereiro a agosto de 2013.

Optamos pelas entrevistas semiestruturadas porque facilitam a delimitação da temática selecionada como objeto de pesquisa e por se constituírem em um gênero que permite a construção de identidades mediante a interação comunicativa (BULEA, 2010). Para este estudo, muitas questões abertas foram feitas aos tutores, para instigá-los a discorrer sobre diversos aspectos de sua atividade, como formação profissional, capacitação contínua, dificuldades na função, conhecimentos solicitados na tutoria, entre outras.

Admitimos, assim como Machado (2009), haver dificuldade de verbalização do trabalhador acerca de seu próprio trabalho, mas como a autora, voltamo-nos também para as dificuldades encontradas nos próprios procedimentos que visam a obter informações a partir de interações orais ou escritas entre um pesquisador e os atores sociais de dado grupo a partir de perguntas. Para haver rigor científico, é necessário que o pesquisador considere a situação da produção de textos produzidos por indução desses procedimentos, os valores do ato de perguntar e as formas de pergunta que favorecem a veiculação das pressuposições do pesquisador sobre a informação demandada (MACHADO, 2009).

Neste estudo, as ações humanas analisadas na vertente teórica do IS são as realizadas pelos tutores na execução de suas tarefas. Dessa forma, buscamos analisar, no nível sociológico, as relações de interdependência entre as propriedades das ações dos tutores em exercício e as propriedades das formações sociais (dentre as quais a formação profissional) que constituem o contexto das ações desses sujeitos. No nível psicológico, buscamos avaliar as representações conscientes dos tutores formadores, suas intenções e motivos no desenrolar de sua ação mediante as entrevistas de pesquisa, procurando avaliar a relevância de suas determinações externas.

Em relação à função do tutor, acreditamos, assim como Franco e Souza (2012), que essa função assume várias significações em conformidade com o tempo histórico no qual está inserido e depende da estrutura organizativa de cada instituição. O significado etimológico dessa atividade ganha novas 
interpretações e exige desse profissional o comprometimento e o conhecimento da EaD. Nesse âmbito, não basta apenas ter a vontade de ser um tutor, é preciso estar envolvido em todo o processo que o constitui, ciente das tarefas e dos conhecimentos necessários para o exercício eficaz de sua atividade. Assim como as autoras, entendemos que a palavra tutor pode ser atrelada às definições de guia, protetor, defensor, diretor, fiscalizador, orientador, dentre outras funções, dependendo da perspectiva pedagógica adotada pelo modelo de EaD.

As ações do tutor, para Franco e Souza (2012) e também percebidas em nossa pesquisa, exigem competências pessoais, tecnológicas, sociais e profissionais organizadas em quatro grandes áreas apresentadas por Tractenberg L. e Tractenberg V. (2007):

1. competências pedagógicas (domínio dos métodos de ensino-aprendizagem) e técnicas (domínio do conteúdo);

2. competências sócio-afetivas (capacidades de criação de um ambiente interpessoal favorável à aprendizagem);

3. competências gerenciais (capacidades de organização e coordenação das atividades e procedimentos relativos ao curso);

4. competências tecnológicas (domínio das tecnologias de informação e de comunicação requeridas para a condução das atividades) (TRACTENBERG L. e TRACTENBERG V., 2007, p.2).

Franco e Souza (2012) e Maggio (2001) salientam que as competências pedagógicas demandam do tutor o conhecimento do conteúdo abordado em todas as disciplinas nas quais sua função será exercida e das técnicas didáticopedagógicas para sua operacionalização no processo de aprendizagem. Ou seja, sua "formação teórica, disciplinar e pedagógico-didática deverá ser atualizada" (MAGGIO, 2001, p.104). Neste estudo, com base na análise das entrevistas dos tutores, assinalamos que as competências pedagógicas e técnicas por parte do tutor são fundamentais para a mediação eficaz e se sobressaem no quesito relevância das demais competências aqui elencadas.

As competências tecnológicas (FRANCO e SOUZA, 2012) requerem a destreza do tutor no uso das tecnologias de informação e comunicação que, na $\mathrm{EaD}$, o habilitarão para a comunicação virtual entre docentes, demais tutores e acadêmicos por meio de ferramentas como e-mail, chat, fórum, videoconferência, dentre outros. Neste estudo, as competências tecnológicas 
do tutor foram também investigadas mediante as entrevistas semiestruturadas. $\mathrm{Na}$ IES em pauta, há preocupação em capacitar o tutor tecnologicamente por meio de cursos de formação contínua específicos, e os tutores são cientes de que essa capacitação contínua é relevante.

Frisamos que os recursos tecnológicos, na $\mathrm{EaD}$, dão suporte à aprendizagem e se entrelaçam com as competências gerenciais e socioafetivas por estarem no computador e no uso da internet os meios para que essas competências se efetivem. Neste estudo, as entrevistas semiestruturadas realizadas com os tutores permitiram depreender como estes utilizam os recursos tecnológicos no momento da mediação dos conhecimentos, e como essas ferramentas tecnológicas são importantes no ambiente virtual de ensino.

Mediante as competências gerenciais, o tutor terá condições de "planejar atividades, administrar o tempo, orientar procedimentos, organizar o trabalho cooperativo dos aprendizes, acompanhar e adaptar as atividades de aprendizagem conforme a necessidade" (TRACTENBERG L. e TRACTENBERG V., 2007, p.2). Neste estudo, observamos essas capacidades gerenciais nos depoimentos dos sujeitos entrevistados, e percebemos a importância do planejamento de seu trabalho na tutoria.

Franco e Souza (2012) assinalam que, longe de serem atividades estritamente técnicas, todos os procedimentos realizados pelos tutores são transpassados por capacidades socioafetivas que dão o tom aos seus discursos e permitem uma comunicação positiva, motivadora e criadora de relacionamentos, em sua maioria virtuais, mas que devem ser alimentados durante todo o curso de graduação a distância sob pena de contribuir para a evasão dos estudantes. Neste estudo, verificamos as capacidades socioafetivas mediante a fala dos tutores formadores na geração de dados a partir das entrevistas semiestruturadas, as quais são reveladoras de uma motivação constante junto aos alunos da graduação.

Mill et al. (2008) propagam que o tutor da EaD é um elemento-chave para o desenvolvimento cognitivo do estudante nas atividades individuais e coletivas ao longo de uma disciplina ou de um curso, pois, na prática, é ele que acompanha, orienta, estimula e provoca o estudante para construir o seu 
próprio saber e para desenvolver processos reflexivos tão necessários em cursos nessa modalidade. Corroboramos essa premissa, pois, na atual configuração dos cursos de EaD no país, o tutor é uma figura imprescindível, sem o qual a estrutura da modalidade não se sustenta.

\section{Alguns resultados}

Compreender a função exercida pelo tutor evidencia a importância de um profissional que atua nos pontos cruciais de um processo complexo como a formação de adultos na modalidade de ensino a distância.

Os resultados das análises das entrevistas junto aos tutores de um curso de Letras a Distância de uma IES pública nos permitiram verificar, por meio das figuras de agir construídas em seus discursos, que estes:

(i) apresentam uma visão ampla e abrangente do que é o trabalho na tutoria, são cientes da relevância de seu papel na EaD, de que possuem capacidades para exercer sua atividade, de que são peças-chave nessa forma de ensino à medida que fazem a mediação dos conhecimentos, orientam, estimulam e incentivam os acadêmicos e se responsabilizam pelas avaliações das atividades repassadas pelos docentes das disciplinas;

(ii) consideram a apropriação dos artefatos digitais/tecnológicos insatisfatória, pois, segundo eles, os cursos oferecidos pela IES não dão conta de prepará-los adequadamente para o uso das ferramentas virtuais na mediação dos conhecimentos junto aos alunos, e requerem mais cursos de capacitação contínua;

(iii) não detêm todos os conhecimentos deles solicitados para efetuar a mediação junto aos acadêmicos do curso e sugerem a divisão de disciplinas por área de conhecimento para maximizar sua prática docente;

(iv) ressentem-se do não reconhecimento de sua profissão e do vínculo inexistente com a IES, como bolsistas da Capes; julgam inadequada a remuneração recebida diante das exigências para ocupar o cargo (nível de pós-graduação e experiência docente); 
(v) revelam agir como alunos na apropriação dos conhecimentos para a mediação no Atendente Virtual de Aprendizagem (AVA): estudam o mesmo material didático, pesquisam demais referências e trocam informações com os demais tutores, além de pedirem orientação aos docentes responsáveis pelas disciplinas do curso;

(vi) reclamam da não participação dos acadêmicos no AVA das disciplinas, pois estes comumente não postam suas dúvidas e interagem minimamente com os tutores, tornando difícil ou inexistente o processo de interação, e consequentemente, de mediação dos conteúdos, objetivo maior da tutoria.

\section{Considerações finais}

Neste estudo, mediante entrevistas realizadas com dez tutores do curso de Letras a Distância de uma IES pública, observamos alguns aspectos revelados pelos sujeitos que evidenciam a representação de suas ações humanas (BRONCKART, 2008) na tutoria. Por meio do agir da linguagem, observamos o agir profissional dos tutores, e analisamos, no nível sociológico, as relações de interdependência entre as ações dos tutores em exercício e as formações sociais; no nível psicológico, avaliamos as representações conscientes dos tutores, suas intenções e motivos no desenrolar de suas ações, pontuando alguns desses aspectos que evidenciam a sua importância na atual configuração da EaD.

Observamos que o desenvolvimento humano (BRONCKART, 2008) do tutor de EaD se constrói no processo social da tutoria de EaD mediado pelos instrumentos digitais e virtuais que este tem à sua disposição, colaborando para seu crescimento profissional e o tornando cada vez mais imprescindível nessa forma de ensino. Os resultados alcançados por este trabalho levam à constatação da relevância do papel exercido por esse profissional nos cursos de graduação a distância e à reflexão de que esse formador precisa ser melhor aproveitado pelas IES que oferecem cursos a distância. 
Referências bibliográficas

ABREU-TARDELLI, L. S. trabalhodoprofessor@chateducacional.com, Aportes para compreender o papel do professor iniciante em EAD. Tese de Doutorado (Linguística Aplicada e Estudos da Linguagem). PUC/SP, São Paulo, 2006, $196 f$.

BAKHTIN, M. M. Estética da criação verbal. 4ํe․, SP: Martins Fontes, 2003 [1992].

BLANCHET, A.; GOTMAN, A. L'enquête et ses méthodes. L' entretien. $2^{\text {a }}$ ed., Armand Colin, 2012.

BRONCKART, J-P; MACHADO, A. R. Procedimentos de análise de textos sobre o trabalho educacional. In: MACHADO, A. R. O ensino como trabalho: uma abordagem discursiva. Londrina: EDUEL, 2004.

BRONCKART, J-P. O agir nos discursos: das concepções teóricas às concepções dos trabalhadores. Campinas: Mercado de Letras, 2008.

BULEA, E.. Linguagem e efeitos desenvolvimentais da interpretação da atividade. Tradução de Eulália Vera Fraga Leurquin e Lena Lúcia Espínola Rodrigues Figueirêdo. Campinas: Mercado de Letras, 2010.

CRISTÓVÃO, V. L. L. (Org.). Estudos da linguagem à luz do interacionismo sociodiscursivo. Londrina, UEL, 2008.

FERREIRA, T. S. F. Representações sobre o agir: caminhos para a compreensão do papel da tutoria na EAD. Dissertação (Mestrado em Linguística). Universidade Estadual da Paraíba, 2011.

FRANCO, V. S.; SOUZA, S. de. O sistema de tutoria no Ensino a Distância. In: COSTA, Maria Luisa Furlan (Org.). Educação a distância no Brasil: avanços e perspectivas. Maringá: EDUEM, 2013.

GUIMARÃES, A. M. de M.; MACHADO, A. R.; COUTINHO, A. (orgs.). 0 Interacionismo sociodiscursivo. Questões epistemológicas e metodológicas. Campinas: Mercado de Letras, 2007.

KOZINETS, R. V. Netnography: doing ethnografic research online. London: Sage, 2010.

HABERMAS, J. Teoría de la acción comunicativa I: racionalidad de la acción y racionalización social. Tradução de Manuel Jiménez Redondo. 4 ed. Madrid: Taurus, 1987.

HINE, Christine. Etnografía Virtual. Barcelona: Editorial UOC, 2004. 
MACHADO, A. R. e colaboradores; ABREU-TARDELLI; L. S.; CRISTÓVÃO, V. L.(Orgs.). Linguagem e Educação: o papel do professor em uma nova perspectiva. Campinas: Mercado de Letras, 2009.

MAGGIO, M. O tutor na educação a distância. In: LITWIN, E. (org.); Educação a Distância: temas para o debate de uma nova agenda educativa. Porto Alegre: Artmed, 200.

MILL, D.; ABREU-E-LIMA, D.; LIMA, V. S.; TANCREDI, R. M. S. O desafio de uma interação de qualidade na educação a Distância: o tutor e sua importância nesse processo. Cadernos da Pedagogia Ano 02, Volume 02, Número 04, agosto/dezembro 2008.

TRACTENBERG L.; TRACTENBERG R. Seis competências essenciais da docência online independente. Disponível http://www.slideshare.net/regist/regis-tractenberg-docencia-online-

independente-10-forum-universitario-pearson-rio-de-janeiro-maio-2012. Acesso em 13/02/2013. 
Artigo recebido em: 30/11/2013

Artigo avaliado em: 04/04/2014

Sobre a autora:

Doutoranda em Estudos da Linguagem na Universidade Estadual de Londrina. 